Supplement of Biogeosciences, 13, 3833-3846, 2016

http://www.biogeosciences.net/13/3833/2016/

doi:10.5194/bg-13-3833-2016-supplement

(C) Author(s) 2016. CC Attribution 3.0 License.

(c) (1)

Supplement of

Identification and analysis of low-molecular-weight dissolved organic carbon in subglacial basal ice ecosystems by ion chromatography

Emily C. O'Donnell et al.

Correspondence to: Emily C. O’Donnell (emily.o'donnell@nottingham.ac.uk)

The copyright of individual parts of the supplement might differ from the CC-BY 3.0 licence. 


\section{Cell counts}

Cell counts were conducted to quantify the microbial abundance in basal sediment and determine whether there is potential for subglacial microbial activity. The methodology was conducted as follows. Briefly, $100 \mathrm{mg}$ of wet sediment was added to $1 \mathrm{~mL}$ of pre-sterilised deionized water (DI) in a sterile Eppendorf tube and mixed by vortexing for 30 seconds. To fix the sample, $0.2 \mu \mathrm{m}$ filter-sterilised $37 \%$ formaldehyde (final concentration 1\%) was added to the tube and vortexed briefly. The suspension was then filtered onto a sterile $0.2 \mu \mathrm{m}$ Anodisc filter (Whatman, Maidstone, UK). Dried filters were placed onto $100 \mu \mathrm{L}$ drops of $2 \times$ SYBR Gold (Invitrogen, Eugene, OR, USA) for $15 \mathrm{~min}$, dried and mounted on microscopic slides with the anti-fade agent Citifluor AF2 (Citifluor, Leicester, UK). For Joyce Glacier samples, the method followed that of (Porter and Feig, 1980). $1 \mathrm{~g}$ of wet basal sediment was combined with $9 \mathrm{~mL}$ of $0.2 \mu \mathrm{m}$ filtered DI in a sterile centrifuge tube and sonicated for 2 mins to liberate cells attached to the sediment. $1 \mathrm{~mL}$ suspensions were transferred to sterile Eppendorf tubes and $10 \mu \mathrm{L}$ 4',6'-diamidino-2-phenylindole (DAPI) (Invitrogen) was added to stain the cells. After 10 minutes, samples were filtered through $0.2 \mu \mathrm{m}$ Anodisc filters and mounted on microscopic slides. All stained cells were enumerated on each slide with an Olympus BX41 epifluorescence microscope (Olympus Optical, Tokyo, Japan). Filter blocks U-N31001 (excitation $480 \mathrm{~nm}$, emission $535 \mathrm{~nm}$ ) and U-MNUA2 (excitation 360-370 nm, emission 420-460 nm) (Chroma Technology, Rockingham, VT, USA) were used to count SYBR Gold and DAPI stained cells, respectively. Two slides per sample were counted. For Joyce Glacier samples, 20 fields of view $(10 \mu \mathrm{m} \times 10 \mu \mathrm{m})$ were counted for each slide (1 slide per sample). Procedural blanks with no basal sediment were counted in parallel and the average blank counts (negligible) were then subtracted from the experimental sample counts.

\section{Reference}

Porter, K.G., and Feig, Y.S. The use of DAPI for identifying and counting aquatic microflora. Limnol. Oceanogr. 25, 943-948, doi: 10.4319/lo.1980.25.5.0943, 1980. 